\title{
Sinovite proliferativa crônica da articulação metacarpofalangiana em equinos: relato de caso
}

\author{
[Chronic proliferative synovitis of the fetlock joint in horses: case report] \\ J.C. Lacerda Neto ${ }^{1}$, K. Gravena ${ }^{2}$, J.C. Canola ${ }^{1}$, J.W. Cattelan ${ }^{1}$ \\ ${ }^{1}$ Faculdade de Ciências Agrárias e Veterinárias - UNESP - Jaboticabal, SP \\ ${ }^{2}$ Aluna de pós-graduação - FCAV-UNESP - Jaboticabal, SP
}

\begin{abstract}
RESUMO
Uma potra da raça Mangalarga foi avaliada clinicamente por apresentar claudicação dos membros torácicos. À inspeção, observaram-se desvios angulares e sensibilidade em ambos os membros, especialmente o esquerdo, que se mostrava sensível à flexão da articulação metacarpofalangiana. Ao exame radiográfico, visualizaram-se imagens compatíveis com sinovite proliferativa crônica da articulação metacarpofalangiana esquerda. A artrografia contrastada positiva confirmou a presença de massa tecidual ocupando a superfície dorsoproximal da articulação. Pela severidade da lesão, realizou-se artrotomia metacarpofalangiana esquerda. Neste caso, optou-se pela remoção do processo proliferativo, que produzia reabsorção óssea de grande intensidade e redução da cortical da epífise distal do metacarpo III, com risco de fratura patológica.
\end{abstract}

Palavras-chave: equino, sinovite, artrotomia

\begin{abstract}
A Mangalarga foal was examined presenting both front limb lameness. The clinical examination revealed angular limb deformity and increased pain sensation, notably on the front left limb, which showed a reduced range of motion on the metacarpophalangeal joint. X-ray images indicated chronic proliferative synovitis in the above mentioned joint. Positive contrast arthrography confirmed a space occupying mass on the dorsoproximal surface of the joint. Due to the severity of the lesion, arthrostomy was performed followed by the removal of the proliferative tissue, to reduce the risk of pathological fracture on the distal end of the metacarpus III.
\end{abstract}

Keywords: horses, synovitis, arthrotomy

\section{INTRODUÇÃO}

A sinovite proliferativa crônica dos equinos é também conhecida como sinovite vilonodular devido à semelhança com a forma nodular da sinovite vilonodular pigmentada na espécie humana. Porém, ao exame histológico, nos cavalos, a massa sinovial não é pigmentada pela hemossiderina. Por esse motivo, é mais apropriado denominar essa afecção por sinoite proliferativa crônica (McIlwraith, 2006).

A membrana interna da cápsula das articulações metacarpofalangiana (AMCF) e metatarsofalangeana (AMTF) dos equinos apresenta na sua porção dorsoproximal, adjacente à inserção óssea, uma pequena projeção no sentido distal da articulação. Esse tecido pode eventualmente passar por um processo de hipertrofia e desenvolver uma massa de aspecto nodular com tendência à cronificação, conhecida por sinovite proliferativa (Dabareiner et al., 1996).

Segundo McIlwraith (2006), essa doença é típica do Puro Sangue Inglês e do Quarto de Milha de corrida, mas já foi relatada em outras raças de equinos, tais como Árabe (Losasso e Honnas, 1994), Standardbred, ou em animais sem raça definida utilizados para salto (Van Veenedahl e Moffatt, 1980).

Recebido em 10 de maio de 2010

Aceito em 17 de março de 2011

E-mail:jlacerda@fcav.unesp.br 
Acredita-se que o movimento excessivo e repetitivo de extensão da AMCF realizado durante a atividade física traumatize a prega sinovial e seja a principal causa do aparecimento desse tipo de sinovite (Kawcak e Trotter, 1996).

As alterações observadas incluem inchaço dos tecidos moles sobre a superfície dorso-proximal da articulação afetada, com consequente distensão da cápsula articular e aparecimento de estímulo doloroso, que se acentua com a flexão da articulação (McIlwraith, 2006). A confirmação da suspeita é feita empregando-se técnicas especiais, como a ultrassonografia ou o exame radiográfico da articulação do boleto (Pool e Meagher, 1990; Denoix et al., 1996; Ueltschi et al., 1996 citados em Vanderperren e Saunders, 2009) e a artrografia, esta última realizada raras vezes por ser um procedimento invasivo (McIlwraith, 2006).

Procedimentos terapêuticos conservativos, utilizando a administração intra-articular de medicamentos e repouso, foram descritos, mas com resultados não satisfatórios (McIlwraith, 2006). Porém, a excisão da massa nodular, tem sido o tratamento de eleição, utilizando-se, para essa finalidade, a artrotomia (Vickers e Ross, 1996), a artroscopia (Kannegieter, 1990) e a extirpação a laser, orientada por artroscópio (Murphy e Nixon, 2001).

O objetivo deste trabalho foi relatar um caso de sinovite proliferativa crônica da articulação metatarsofalangeana em uma potra.

\section{CASUÍSTICA}

Uma potra Mangalarga, com oito meses de idade, foi examinada em Hospital Veterinário Escola, para avaliação de claudicação no membro torácico esquerdo. À inspeção, observou-se desvio varo da AMCF e aumento da sensibilidade articular. Ao exame radiográfico, constatou-se redução do espaço articular na face medial, rarefação e irregularidade ósseas, além de osteófitos intra e periarticulares. Aspectos semelhantes foram observados no membro contralateral. O animal apresentava, ainda, desvios angulares valgo dos carpos e rotação bilateral medial das pinças dos cascos. $\mathrm{Na}$ oportunidade, indicou-se natação, três vezes por semana, como fisioterapia. Decorridos cinco meses, como não houve melhora da condição, o animal foi reexaminado, ocasião em que mostrava sensibilidade e claudicação de grau 2 no membro torácico esquerdo.

$\mathrm{Na}$ abordagem radiográfica dorsopalmar, detectou-se aumento de densidade óssea da cortical lateral do terceiro metacarpo esquerdo. Mais uma vez, indicou-se repouso de três meses e retorno após esse período. Passados 15 meses, o animal retornou por apresentar claudicação grau 1 no membro torácico direito e por manter o mesmo grau de claudicação no membro torácico esquerdo, que se mostrava sensível à palpação da AMCF. Ao exame radiográfico simples, visualizaram-se imagens compatíveis com sinovite proliferativa crônica da AMCF esquerda, caracterizadas por aumento de volume na região dorsal e reabsorção óssea, junto ao local de inserção da cápsula articular.

O artrograma com contraste positivo foi realizado para avaliação das alterações morfológicas. Após desinfecção cutânea da bolsa volar da AMCF, localizada entre o terceiro metacarpiano e o ligamento suspensor do boleto, efetuou-se a infusão de $8 \mathrm{~mL}$ de contraste radiopaco, solução de iopamidol (Iopamiron®300,Schering, São Paulo-SP).

Mediante os achados radiográficos, optou-se por terapia radical, indicando-se a artrotomia. Após jejum overnigth, a potra foi anestesiada e colocada em decúbito lateral. A AMCF esquerda foi assepticamente preparada para artrotomia, realizada por meio de acesso dorsolateral. A massa foi removida mediante diérese cruenta. Exame da cavidade articular foi, então, realizado, constatando-se que o tecido ósseo subcondral estava erodido pelo tecido sinovial proliferativo. A articulação foi lavada, a incisão de pele suturada e uma bandagem estéril foi aplicada. A potra recuperou-se da anestesia sem complicações.

Um fragmento do tecido nodular removido foi encaminhado para exame histológico. Na análise, constatou-se proliferação de tecido de granulação com grande quantidade de colágeno e numerosos vasos neoformados. Não havia nenhuma característica de tecido neoplásico. 


\section{Lacerda Neto et al.}

\section{DISCUSSÃO}

Embora haja muita especulação inconclusiva sobre a etiologia da sinovite proliferativa, sua origem é atribuída, segundo Kawcak e Trotter (1996), aos processos traumáticos entre a projeção da membrana sinovial e a face dorsal da falange proximal, decorrentes de extrema hiperextensão causada pela atividade física excessiva. A possibilidade do envolvimento de um segundo fator casual nesse tipo de lesão foi sugerida por Vickers e Ross (1996), que atribuíram a ocorrência de lesão proliferativa sinovial em um equino à implantação de células epiteliais durante artrocentese. Esta massa pode causar alterações degenerativas sobre a superfície articular, com subsequentes sinais de doença articular e claudicação. Entretanto, o caso aqui estudado desenvolveu-se em um animal jovem, ainda não utilizado em atividades esportivas, e que não havia sido submetido à punção articular. Porém, apresentava graves alterações na conformação dos seus membros torácicos, inclusive da articulação do boleto.

O exame radiográfico simples revelou a existência de concavidade na porção cortical da extremidade dorsodistal do terceiro metacarpiano (Fig. 1-A). A erosão da cortical do osso é, de acordo com Rose (1988), evidência de um diagnóstico de sinovite vilonodular com indicação para artrograma com administração de contraste positivo intra-articular. Neste caso, a técnica contrastada revelou a presença de massa tecidual ocupando a superfície dorsoproximal da referida articulação (Fig. 1-B). As lesões erosivas observadas na cortical óssea resultam, segundo Kannegieter (1990), da necrose causada pela compressão da massa nodular sobre o terceiro metacarpo. Uma outra teoria afirma que a concavidade produzida é resultante de crescimento de tecido sinovial por meio do forame vascular do osso (Nickels et al., 1976).
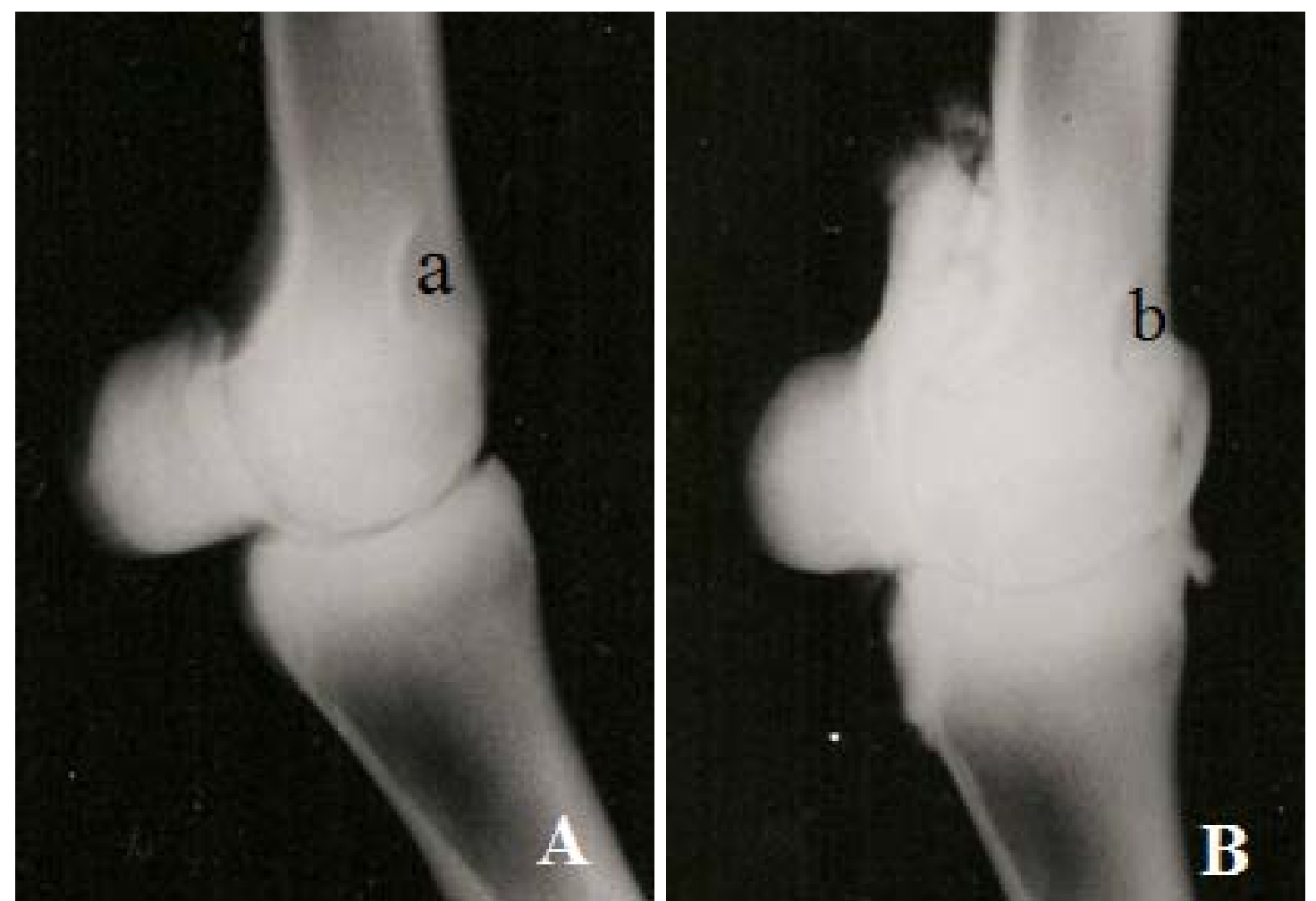

Figura 1. Equino. Radiografia lateromedial da articulação metacarpofalangiana. A - Erosão da cortical óssea na extremidade distal do osso terceiro metacarpiano (a), na região dorsal correspondente ao ponto de inserção da cápsula articular. B - Artrograma do boleto com contraste positivo. Visualização de massa de tecido sinovial na porção dorsoproximal da articulação metacarpofalangiana. A sinovite proliferativa provoca um defeito de preenchimento (b) na porção dorsoproximal da bolsa articular. 
O aspecto microscópico da sinovite proliferativa observado no fragmento analisado é característico de processo inflamatório crônico, cuja descrição coincide com a de McIlwraith (2006). Esse autor refere-se a um componente principal constituído de tecido conjuntivo fibroso denso, com nódulos contendo proliferação vascular e, com frequência, circundado por regiões de necrose de colágeno. As células inflamatórias são pouco observadas na lesão e há ausência de uma camada superficial de sinoviócitos. Nenhuma característica de malignidade é encontrada. Os achados observados ao exame histológico, neste caso, demonstraram a presença de colágeno e foram compatíveis com processo inflamatório.

O tratamento de eleição é a remoção cirúrgica completa da massa nodular. No homem, a excisão incompleta do tecido sinovial proliferativo é, possivelmente, a causa de reaparecimento da condição (Wright, 1951) e, provavelmente, também o é nos equinos submetidos ao tratamento cirúrgico (Rose, 1988). A utilização do acesso dorsolateral mostrou-se plenamente eficaz tanto na abordagem da bolsa articular dorsal como na remoção de massa tecidual que ocorreu na sua totalidade.

Radiografias seriadas, tomadas aos 30, 60, 90 e 120 dias após o ato cirúrgico, não mostraram remodelamento das lesões, porém o quadro clínico de claudicação melhorou acentuadamente, passando a ser de grau 1. Em razão da má conformação e consequentes lesões degenerativas articulares dos boletos, foi recomendado que o animal não participasse de provas esportivas.

\section{REFERÊNCIAS BIBLIOGRÁFICAS}

DABAREINER, R.M.; WHITE, N.A.; SULLINS, K.E. Metacarpophalangeal joint synovial pad fibrotic proliferation in 63 horses. Vet. Surg., v.25, p.199-206, 1996.

DENOIX, J.M. US examination in the diagnosis of joint disease. In: McILWRAITH, C.W.; TROTTER, G.W. Joint disease in the horse. Philadelphia: Saunders, 1996. p.165-202.

KANNEGIETER, N.J. Chronic proliferative synovitis of the equine metacarpophalangeal joint. Vet. Rec., v.127, p.8-10, 1990.
KAWCAK, C.E.; TROTTER, G.W. Other conditions affecting equine joints. In McILWRAITH, C.W.; TROTTER, G.W. Joint disease in the horse. Philadelphia: Saunders, 1996. Cap. 25. p.410-419

LOSASSO, M.B.; HONNAS, C.M. Chronic proliferative synovitis in a horse. Equine Pract., v.16, p.29-32, 1994.

McILWRAITH, C.W. Doenças das articulações, tendões, ligamentos e estruturas relacionadas. In: STASHAK, T.S. Claudicação em equinos segundo Adams. 5.ed. São Paulo: Roca, 2006. Cap. 7, p.417-601.

MURPHY D.J.; NIXON A.J. Arthroscopic laser extirpation of metacarpophalangeal synovial pad proliferation in eleven horses. Equine Vet. J., v.33, p.296-301, 2001.

NICKELS, F.A.; GRANT, B.D.; LINCOLN, S.D. Villonodular synovitis of the equine metacarpophalangeal joint. J. Am. Vet. Med. Assoc., v.168, p.1043-1046, 1976.

POOL, R.R.; MEAGHER, D.M. Pathological findings and pathogenesis of racetrack injuries. Vet. Clin. N. Am.: Equine Pract., v.6, p.1-30, 1990.

ROSE, P.L. Villonodular synovitis in horse. Compend. Equine, v.10, p.649-654, 1988.

UELTSCHI, G.; VOSWINKEL, K.; LAUK, H.D. Scintigraphical and radiological examination of fetlock-joints in clinically sound and lame horses. Pferdeheilkunde, v.12, p.25-32, 1996.

VANDERPERREN, K.; SAUNDERS, J.H. Diagnostic imaging of the equine fetlock region using radiography and ultrasonography. Part 1: Soft tissues. Vet. J., v. 181, p.111-122, 2009.

VAN VEENEDAHL, J.C.; MOFFATT, R.E. Soft tissues masses in the fetlock joint of the horses. Aust. Vet. J., v.56, p.533-536, 1980.

VICKERS, K.L.; ROSS, M.W. Atypical villonodular synovitis in a horse. J. Am. Vet. Med. Assoc., v.209, p.1602-1603, 1996.

WRIGHT, C.J.E. Benign cell synovioma. An investigation of 85 cases. Br. J. Surg., v.38, p. 257-301, 1951. 